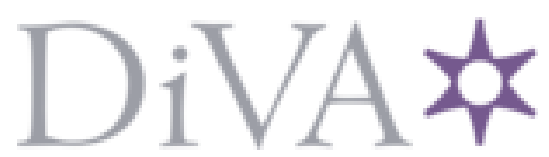

http://www.diva-portal.org

This is the published version of a paper published in Energy Research \& Social Science, Special Issue on Renewable Energy in Sub-Saharan Africa: Contributions from the Social Sciences.

Citation for the original published paper (version of record):

Eder, J., Mutsaerts, C., Sriwannawit, P. (2015)

Mini-grids and renewable energy in rural Africa: How diffusion theory explains adoption of electricity in Uganda.

Energy Research \& Social Science, Special Issue on Renewable Energy in Sub-Saharan Africa:

Contributions from the Social Sciences, 5: 45-54

http://dx.doi.org/10.1016/j.erss.2014.12.014

Access to the published version may require subscription.

N.B. When citing this work, cite the original published paper.

Permanent link to this version:

http://urn.kb.se/resolve?urn=urn:nbn:se:kth:diva-161216 
Original research article

\title{
Mini-grids and renewable energy in rural Africa: How diffusion theory explains adoption of electricity in Uganda
}

\author{
Jonas M. Eder ${ }^{\mathrm{a}}$, Christopher F. Mutsaerts ${ }^{\mathrm{b}}$, Pranpreya Sriwannawit ${ }^{\mathrm{c}, *}$ \\ ${ }^{a}$ Faculty of Management, University of Trier, Trier, Germany \\ b BearingPoint, Amsterdam, The Netherlands \\ c Department of Industrial Economics and Management, KTH Royal Institute of Technology, Stockholm, Sweden
}

\section{A R T I C L E I N F O}

\section{Article history:}

Received 29 June 2014

Received in revised form

15 December 2014

Accepted 18 December 2014

Available online 22 January 2015

\section{Keywords:}

Africa

Biomass

Household

Low-income market

Renewable energy

Rural electrification

\begin{abstract}
A B S T R A C T
With diffusion theory as the point of departure, this study analyses the factors that influence the adoption of renewable electricity from individual households' perspectives. The analysis is based on a case study provided by a Swedish energy service company operating in rural Uganda. The company distributes electricity to rural households via a mini-grid powered by a biomass gasification system. Three critical dimensions are identified to be crucial for adoption: technical, economic, and social. First, there is an emphasis on the relative advantages of the new technology. Second, there are economic requirements regarding a viable financial system for adopters, especially in such a low-income market. Third, the social dimension is critical, particularly the importance of foreign firms collaborating with local actors. We further suggest that a lack of understanding of local communities can lead foreign companies to fail in diffusion attempts. While we focus on Uganda, the results of our research are highly relevant for foreign actors who attempt to penetrate rural markets in developing countries in general.
\end{abstract}

(c) 2015 Elsevier Ltd. All rights reserved.

\section{Introduction}

Electricity access is crucial for development, particularly among low-income inhabitants of developing countries [1] (see Mukasa et al. [2] in this Special Issue for a review of the literature showing that the causation is not always straightforward). However, 1.3 billion people worldwide spend their lives with no access to electricity, nearly half of them in sub-Saharan Africa [3]. Because of limited financial resources and the dispersed and scarce availability of infrastructure in rural areas of sub-Saharan Africa, the equitable distribution of electricity via a national grid is difficult to achieve. Hancock [4], in this Special Issue, discusses the hurdles in the wider implementation of renewable energy in Sub-Saharan Africa, which underlines the importance of empirical investigation in this region. Moreover, climate change challenges emphasise the urgent need for a shift from traditional fossil fuel-based electricity production. Additionally, innovation in the technological infrastructure and production and use of energy could potentially

\footnotetext{
* Corresponding author. Tel.: +46 87908735 .

E-mail addresses: jed@munich-innovation.com (J.M. Eder), chris.mutsaerts@bearingpoint.com (C.F. Mutsaerts). pranpreya.sriwannawit@indek.kth.se (P. Sriwannawit).
}

be beneficial to climate change mitigation [5]. Thus, efforts to introduce small and medium-sized renewable energy systems should be based on international technology transfer, i.e., from developed to developing countries [6]. Innovative energy systems have proven to enhance quality of life and potentially stimulate entrepreneurship [7].

This study focuses on Uganda, where only approximately $4 \%$ of the population in rural areas has access to electricity [8]. Because of the poor infrastructure, the national grid can only be found along the main roads that connect the major cities. Therefore, people without access to the grid use alternative energy sources such as kerosene and diesel engines. Furthermore, Ugandans may perceive charcoal as a non-sustainable energy alternative because of its potential to harm the environment [9]. In addition to the improvements stated by Musinguzi et al. [7], enabling electricity access for the remaining $96 \%$ can also have a positive impact on welfare and the sustainability of livelihoods [10-12]. There are, however, two main reasons that connecting these people to the national grid is neither realistic nor feasible. First, it is a matter of the prioritisation of municipalities and governmental institutions because there exist multiple other economically attractive opportunities. Second, Uganda has only limited capacity for power generation. One way to solve this lack of electricity access could be the use of decentralised power generation technologies. Ideally, these should 
be through renewable sources, the subject of this Special Issue. However, there are hurdles both to providing these technologies, and to getting people to adopt them.

There is a significant literature on the diffusion of product innovations for low-income communities in developing countries. However, few scholars have investigated how the failure of technology transfer and diffusion can be reduced or managed. Our research attempts to provide these insights, drawing on existing literature as well as new empirical data. We chose to use case study analysis to assess a rural Ugandan village with a power plant operated by a Swedish energy company. Because of the urgent need to enable electricity access in sub-Saharan Africa and the lack of empirical research in this context, this study sheds light on the early stages of diffusion. Taking its theoretical point of departure from the diffusion theory of Rogers [13], this company's approach - distributing biomass-based electricity through a mini-grid - was analysed from a multidimensional perspective. We chose this specific company because of its innovation in the sub-Saharan context. Similar bioenergy technologies have been introduced in Uganda, but they have not yet been widely adopted [14]. Buchholz et al. [15] addressed a multidimensional approach to assess the different contexts in which sustainable bioenergy systems are embedded. To utilise the full potential of biomass residues, additional research is required that should, according to Okello et al. [16], address the technological, economic, and social dimensions that increase the adoption of innovation within social systems. Fri and Savitz [5] stress that the movement through different stages of diffusion is not linear and requires complex feedback loops. The aim of this study is to identify the factors of each dimension that influence the adoption of renewable electricity from individual households' perspectives with empirical insights.

Section 2 discusses the theoretical foundations of this study, with a focus on the diffusion of innovation in developing countries and how this phenomenon is embedded within socio-technical systems. Section 3 provides an overview of the energy service company that we used for our case study. Section 4 describes our research approach and Section 5 discusses our findings. The article ends with conclusions and implications.

\section{Literature review}

This section discusses the theoretical complexity and mechanisms of diffusion process based on three main themes: innovation in developing countries, diffusion process, and the interplay within socio-technical systems.

\subsection{Innovation in developing countries}

Entering a developing country with an innovation that is perceived as new within the social system is always a process rather than a product breakthrough. This process is not a single event that occurs at a specific point of time; rather, it is necessary to transfer knowledge and skills so that the innovation is successfully adopted [17]. Other scholars such as Schumpeter [18] state that to achieve overall increased value, a specific new innovation must be perceived as significantly better than its preceding version. An innovation is defined by Rogers [13, p. 12] as "an idea, practice, or object that is perceived as new by an individual or other unit of adoption".

When an innovation becomes accessible to people within a social system, it can potentially quickly sweep through and take over competing solutions. If this occurs, the innovation is labelled disruptive $[19,20]$. Initially, a disruptive innovation must compete with existing innovations, but eventually it is able to capture the entire market $[20,21]$. In low-income markets, a space can be reached in which disruptive innovations and thus new competition can arise [19]. According to Prahalad [22], targeting low-income communities in developing countries should be a key to businesses' central mission to create sustainable energy, products, and innovations. To be successful in these communities, companies should activate, inform, and involve low-income populations. Co-creating a market that fulfils the needs of this segment can help to alleviate and overcome poverty [23]. Karnani [24] suggests that reducing poverty is only possible by increasing a community's real income, which can be achieved by either lowering prices or increasing its disposable income. Providing access to renewable energy may be one of the keys to raising disposable income.

Multiple scholars argue that innovations in developing countries are exposed to local barriers and conditions, especially in the areas of energy [25] and business modelling [26]. Aubert [27] states that in developing countries, these barriers can be low incomes, low education levels, and bureaucratic organisational structures that hinder the successful promotion of the innovation. Furthermore, a lack of logistical infrastructure slows the diffusion. Wüstenhagen et al. [28] confirm that the transfer of new energy technologies is bound to certain infrastructures. Another impediment to technology transfer and diffusion is that the innovation can be misinterpreted or incompatible with the values of a specific targeted system. This observation is aligned with a study of Troncoso et al. [29] on the social perceptions of a technological innovation that was implemented in rural Mexico. This study shows that adoption is restricted by potential adopters' perceptions. Troncoso et al. [29] note that businesses need an implementation strategy that targets different adopter behaviours, as well as a long-term vision. Additionally, in a study focusing on the assessment of bioenergy alternatives in Uganda, Okello et al. [16] found that the adoption rate of bioenergy technologies can potentially increase if policies can make it more affordable.

\subsection{Diffusion of innovation}

Rogers [13, p. 5] describes diffusion as "the process in which an innovation is communicated through certain channels over time among the members of a social system". This subsection discusses the theoretical foundations of diffusion theory based on four elements: innovation, communication channels, time, and social systems; as well as a potential "chasm" [30] between the early adopters and the adopting majority.

Various individuals and population groups may perceive the same innovation differently, depending on certain characteristics. The first and perhaps most obvious attribute that adopters seek in new technology is relative advantage: "the degree to which an innovation is perceived as better than the idea it supersedes" [13, p. 212]. Greenhalgh et al. [31] emphasise that potential users will likely not consider the innovation if they do not see relative advantages, which are foremost measured in economic returns. Moreover, there are decisive social factors such as user satisfaction and prestige that influence an individual's perception of the relative advantage of innovations. Furthermore, Rogers [13] discusses four additional aspects that affect adoption: compatibility, complexity, trialability, and observability.

Communication is the process through which information is created, received, and shared. A main goal is to achieve mutual understanding among the participants. The two most powerful communication channels are mass media and the interpersonal exchange of information. The latter is more powerful in convincing a social system to accept a new innovation [13]. 


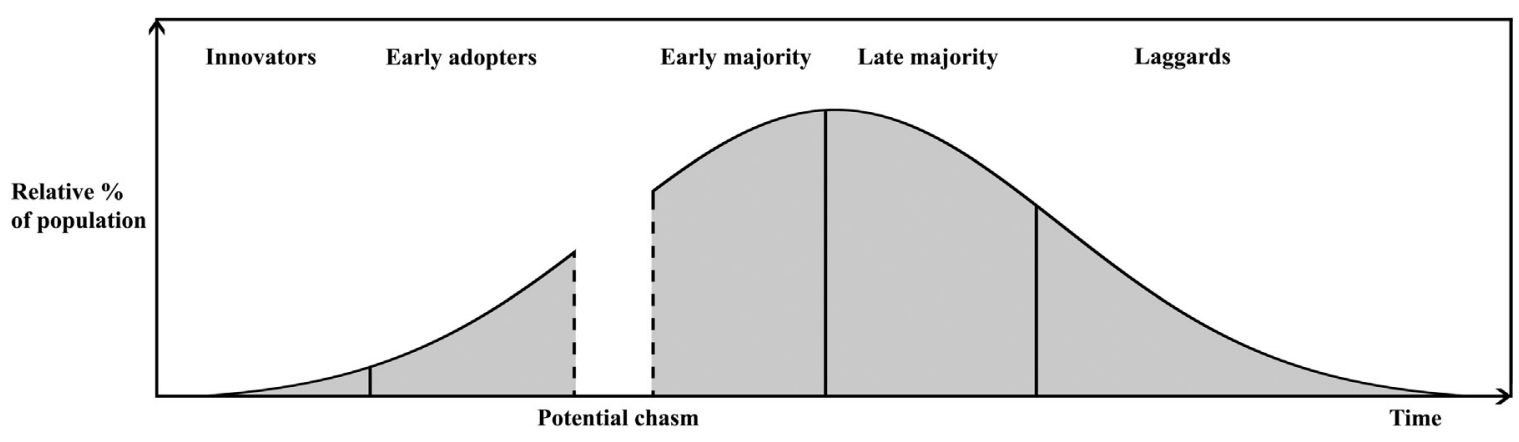

Fig. 1. Adoption curve and the chasm.

The time dimension describes how an individual passes from first exposure to the innovation until its adoption or rejection. This timeframe can differ and is referred to as an innovation's rate of adoption [13]. This rate of adoption is defined by Rogers [13, p. 221 ] as "the relative speed with which an innovation is adopted by members of a social system".

Rogers [13, p. 24] defines a social system as "a set of interrelated units that are engaged in joint problem-solving to accomplish a common goal". Units in a system can differ in their behaviour by means of homo- and heterophily: homophily refers to the similarity between individuals, e.g., regarding education level, beliefs, and social status; whereas heterophily is when individuals differ on these attributes. One distinctive challenge is that individual adopters are often heterophilous. This makes it difficult for an actor attempting to diffuse an innovation to choose only one single approach [13]. For effective diffusion, firms must adapt their strategy to the local context of a given social system.

Fig. 1 shows the points in time at which different groups adopt innovations. The distinction between the different adopter groups is based on behavioural characteristics regarding innovativeness and corresponding to normal distribution statistic percentages. Innovators are those who want a certain product as soon as it becomes available, are willing to take risks, and have financial capabilities. They are cosmopolites who act and have contacts regionally and globally. Early adopters are a larger group who also seek new products but are less sensitive to "hype" (e.g., they look more into functionality). The early majority is the first mass of people to adopt a product, and this is where the curve reaches maturity. The late majority adopts when the majority of the market is already familiar with the product. Sales tend to slow during this phase. Finally, the laggards adopt when the product is soon to be removed from the market. These adopters are more price-sensitive and sceptical [13].

Typically, the adoption process begins relatively slowly, but once a critical mass is reached, it becomes an automatic mechanism that forms an S-shaped curve. This critical mass is one reason that, after a relatively slow start, the rate of adoption can form an S-shaped curve. During the diffusion process, influence can be exerted between adopter groups. Individuals who are influential within the social system and who spread information about an innovation are defined as opinion leaders. They are often local and generally to be found among the early adopters who have the highest degree of opinion leadership [13,21].

According to Moore [30], there can be gaps between different adopter groups. One of the most important gaps is between the early adopters and the early majority, defined as the chasm (see Fig. 1). This occurs when a new product or service cannot be translated into a significant benefit [30]. Early adopters can create bad references for the early majority.

\subsection{Socio-technical systems in energy research}

Transitional change in systems, of which diffusion is an element, affects the diffusion of innovations. Based on historical examples of transitions and system changes, Geels and Schot [32] define a number of types of transition pathways, "transformation, reconfiguration, technological substitution, and de-alignment and re-alignment" [32, p. 399], which differ for interactions on multiple levels in terms of timing and nature. Rip and Kemp [33] and Geels [34] differentiate three levels by which the multilevel vision can be perceived: niche innovations, socio-technical regimes, and sociotechnical landscapes. The process is described as small networks of actors that support new ideas within the niche innovation space and become aligned over time. This movement is subject to external influences on the niches. At the same time, the socio-technical landscape provides opportunities for novelties, such as changing markets, user preferences, and technologies, which leads to a new configuration of the landscape [32]. Simultaneously, this new established regime influences the landscape over time.

Taking a system approach into account, Stern [35, p. 41] argues that "the metaphor of a map is more than a little inadequate because the territory of Energy Research and Social Sciences is highly multi-dimensional". Therefore, Stern [35] introduces a multidimensional perspective with three different dimensions. In technological development, expectations and diffusion scenarios play an executing role-that is, they are crucial resources in the creation of niches [36]. The roles of promises, expectations, and diffusion scenarios within technological development have been investigated by van Lente [37], both theoretically and empirically. This research suggests that when a new technological opportunity evolves, its advocates construct promises and diffusion scenarios to inform and convince relevant communities of its potential. When these promises are translated into concrete requirements, resources such as financing may become available to enable the required activities.

The diffusion of innovation is quite complex, especially in developing countries. Adopters' perceptions can be crucial. This has been scrutinised by Shyu [38], who investigated the mini-grid electricity supply in rural China. This study indicates that diffusion from the end-users' perspectives includes multiple levels of social explanation such as satisfaction, supply, behaviours, and positive and negative experiences. Shyu [38] later concludes that the adopters were not satisfied by the innovation because the provided electricity services were insufficient and unreliable. A similar study by Mallett [39] shows that social acceptance is often neglected in the adoption of renewable technology. The author qualitatively investigated the social acceptance of solar water heaters in Mexico City based on the Rogers diffusion model, which she argues requires revision regarding the effects of technology cooperation. 
Furthermore, a socio-technical case study in Ethiopia by Müggenburg et al. [40] reveals the negative aspects of a small-scale energy system. They conclude that the users' evaluations regarding the performance of the technologies in the field tests were contrary to the lab results. Additionally, negative aspects were discovered during the field test such as jealousy and envy that emerged in the community: As a consequence of the mistrust within the community, users carried the devices with them instead of leaving them at home to recharge. In addition, the study indicates that if products are perceived to be of poor quality, sales can decrease, and their later adoption can be hindered. This phenomenon implies that even low-income inhabitants are willing to pay a surplus for quality products [40]. On the other hand, recent studies have shown successful renewable energy adoption when a research team works directly with the local population to ensure their full participation in decision-making. For example, in this Special Issue, Ahlborg and Sjöstedt [41] conducted a case study on a hydropower in Tanzania and Ulsrud et al. [42] on a solar project in Kenya.

\section{Overview of the energy service company}

This research is based on a case study provided by a Swedish energy service company called Pamoja Cleantech AB (henceforth, Pamoja). Although Pamoja's head office is located in Stockholm, its operational business takes place in rural Uganda. The site that was examined is located in a small village named Tiribogo. Prior to the company's operation, the village had no access to electricity from the national grid. The company installed a small-scale biomass gasification power plant. The gasifier runs on agricultural biomass residues such as maize cobs and coffee husks provided by local farmers. The attached generator produces a power output of 32 kilowatts $(\mathrm{kW})$, which is distributed to the households via a minigrid.

Recent studies reveal that biomass is a high-potential source of energy for Uganda [16,43]. Modern bioenergy technologies have been introduced, but their diffusion remains limited. A reason might be that many of these systems are still not mature and only successful in niche markets rather than being ready for wide application [44]. Despite being economically competitive compared to other alternatives, biomass gasification is not yet widely used in Uganda. These studies emphasise the need to understand this low level of diffusion in terms of policy and business plans [16,43]. Thus, our case study of a foreign energy service company can help to shed light on the dissemination challenge.

This specific site was chosen because it was the first project initiated by Pamoja and was therefore highly suitable for extracting lessons applicable to inexperienced companies entering foreign markets. In the beginning of our fieldwork, only a handful of the approximately 120 households had been connected to electricity; hence, the adoption process was only beginning. Additionally, the mini-grid distributed electricity to the households for the first time only after the first week of our fieldwork; thus, it was possible to identify the initial reactions to this electricity concept, which was completely new in the village. Enabling access to renewable electricity based on biomass gasification using a mini-grid can be considered a disruptive innovation for this community because the electricity was provided throughout the whole village via a grid rather than as stand-alone solutions such as diesel engines and solar panels, which already existed but were limited to the wealthy households.

Pamoja partnered with a local businessman (henceforth, the site manager) from Uganda's capital who was responsible for organising the workforce and materials as well as for the communication with the villagers of Tiribogo. Another important partner was the
Centre for Research in Energy and Energy Conservation (CREEC) from Makerere University, which helped to approach the village and provided technical expertise.

There was no clear pricing structure communicated to the villagers, neither during nor before the fieldwork. There had only been informal, unofficial discussions that electricity would cost each household 20,000-30,000 Ugandan shillings (UGX) ${ }^{1}$ per month. ${ }^{2}$ It was initially agreed that there would be a trial period of one month during which Pamoja would provide electricity free of charge. Apart from that, the households had to incur the costs for grid connection.

According to the company's business model, private households and entrepreneurs that use machines and devices should be connected to electricity. Identifying themselves as social or inclusive entrepreneurs, Pamoja's primary aim was not only to earn revenue but also to support the development of the community and provide electricity to low-income households.

\section{Research approach}

This research describes a qualitative case study drawn from the diffusion and socio-technical system frameworks. A case study is a suitable research tool for investigating questions that integrate different types of evidence [46] comprising both primary and secondary data. The secondary data were drawn from extant literature by means of a search and selection strategy. The primary data were collected during the fieldwork in Uganda, which spanned the course of eight weeks in 2013. Four different methods were applied to collect the primary data: focused interviews, a survey, observation, and expert interviews.

Focused interviews were chosen to gain insights from the villagers of Tiribogo, the potential adopters. This method is recommended for investigating interviewees' subjective perceptions in different social groups [47]. With the assistance of two local interpreters, we conducted focused interviews with 31 individuals, each from a different household. ${ }^{3}$ The interviewees were purposively selected to capture all-encompassing opinions. The selection was based on geographical location within the village, income level, age, gender, and whether the interviewees had adopted electricity. As suggested by McDermott and O'Dell [48], we created an atmosphere of knowledge sharing by introducing the company and ourselves as well as explaining the purpose of our research prior to the interviews.

To complement the interviews, a survey translated into the local language was distributed to the same interviewees to verify their statements from the interviews and obtain a more detailed measure of the villagers' subjective feelings, preferences, and interests, as recommended by Bickman and Rog [49]. For each question, there were five possible answers: completely agree, agree, disagree, completely disagree, and do not understand/no opinion. We included shadow questions, meaning that the same questions were asked twice, appearing reversed the second time. These questions were mainly used to increase the reliability of statements from the interviews, in which many of the questions from the surveys had already been addressed. Six surveys had to be excluded. ${ }^{4}$ Thus, our analysis is based on 25 surveys. $^{5}$

\footnotetext{
1 In 2013, \$1 equaled about 2,600 UGX

2 Gross National Income in Uganda is $\$ 510$ per capita [45]. It should be noted that the adopters in our study reside in rural areas and their income is lower. For more information about prices and income, see Section 5.2.2.

${ }^{3}$ In the results and discussion section, the number of interviewees always refers to the total amount of 31 .

${ }^{4}$ Three were misunderstood, and three were not completed in time.

${ }^{5}$ In the results and discussion section, the number of surveys refers to the total amount of 25 , unless stated otherwise.
} 
Concurrently, participant observation aimed to understand individuals' meanings and interactions from an insider perspective [50]. During the first weeks of the fieldwork, we made multiple visits to the village and grew acquainted with the villagers via a number of means, including working as semi-electricians in their houses, to gain their trust and increase our understanding of their perceptions. The observation improved our understanding of the results from the focused interviews and surveys. It also allowed us to validate certain statements such as regarding income and allowed for the possibility of discussions on more sensitive topics.

Finally, five expert interviews were conducted. The interviewees had expertise in the area of rural electrification and development. As suggested by Flick [47], we systematised each expert interview by addressing electricity, social structures, adoption, financial issues, and business development in Uganda in an attempt to complement the insights attaining from the other data collection methods.

Considering the large amount of primary data from the villagers, our analysis is mainly based on the households' perspectives. End-users' perspectives are important to understand the diffusion process. This practice has been used in other studies that investigate rural electrification in an attempt to understand the interplay of the social aspect of energy research [38-40,51]. Our analysis presented in the next section was drawn from the combination of multiple sources, which allowed us to triangulate and validate the data.

\section{Results and discussion}

The diffusion of an innovation within a social system in a developing country depends on a number of factors [13]. In this study, we particularly emphasise the aspects that were influenced by the rural households' perceptions, which led to the decision of whether to adopt the provision of electricity by a mini-grid. In this section, we discuss the findings of the fieldwork with respect to the literature. To begin, we elaborate on the social system of Tiribogo. Subsequently, we structure our analytical lens based on our empirical finding into three dimensions of diffusion, each with its identified factors, which we believe can help energy service companies to cross the diffusion chasm. Structuring an analysis from a multidimensional perspective is commonly used, including by authors such as Turnheim and Geels [52] and Stern [35]. In addition, and specifically based on experience in the Ugandan context, Buchholz et al. [15] suggest that systems that address sustainable bioenergy generation depend on multiple stakeholders and are always integrated in multiple contexts such as social, economic, and environmental.

\subsection{Understanding the interactions and the local social system}

Tiribogo is a village with approximately 600 inhabitants, most of whom were born there. Nearly all villagers are farmers; most of them grow their own food while producing some cash crops and holding a few animals for income generation. There are a few small bars and shops where the villagers socialise in the evening. We identified two important institutions in Tiribogo: a local committee and a farmers' association.

The local committee consists of nine members, including a chairman and a secretary. The local committee makes decisions about infrastructure, development, and regulations in the village. Of the 31 interviewees, 24 responded that the most influential person was the chairman, when asked whether there were persons who were more important than others in the village. Hence, we consider him an opinion leader in this social system. In terms of income or social class, the chairman did not greatly differ from the other villagers. As stated by the chairman himself, he was elected because the villagers trusted him and valued his problemsolving abilities. The secretary is responsible for organisational and communication matters, such as planning village meetings and informing locals about the committee's decisions. In comparison with the chairman, the younger secretary reported having a rather high income and was very open to new technology. However, according to the focused interviews and our observation, his influence did not appear to be completely accepted by all actors in the social system. He was identified as an opinion leader, even though he displayed some of the characteristics of an innovator.

The farmers' association consists of approximately 30 members. The members collaborate by sharing knowledge and advice, maintaining a collective bank account, and using commonly owned machines and trucks. Especially in the harvesting season, they share workforce and machinery. We identified one wealthy and welleducated farmer as the major advisor to other members; he had a number of trucks and organised the transportation of the cash crops to Uganda's capital. Still, he is rarely seen at local events but focuses on farming; he has a great deal of machinery and property, a diesel engine, and many business contacts outside the village. As a result, he is identified as an innovator.

Based on the focused interviews, expert interviews, surveys, and observation, it was possible to categorise the households into four different tiers (A-D) regarding their standards of living. The classification was based on housing, work (e.g., amount of land owned), food, means of transportation, education, expenditures, incomes, and usage of mobile payments and banks. We elaborate further regarding education and the use of mobile payments and bank accounts as examples.

Households in tier D have only primary school education and share one mobile phone per household, which they use for calls and text messages. Households in tier $C$ have at least primary education and use mobile payments. Those in tier B have mostly secondary education, and some of their children attend private schools; they also use mobile payments and have bank accounts for savings. Finally, tier A households are well educated, and their children attend boarding schools or even university; they use their bank accounts not only for savings but also for transactions.

Based on the interviews and observations, all tier A, most tier B, very few tier $C$, and no tier $D$ households had adopted electricity, as depicted on the left side of the chasm in Fig. 2. Because the innovation was in a very early phase of diffusion, we identify the adopters as belonging to the groups of innovators and early adopters. The two opinion leaders-the chairman and the secretary of the local committee-and the innovator, the advisor to the farmers' association, had adopted the innovation. We identify them as belonging to tiers B, A, and A, respectively. Moreover, we identify a chasm between this group of adopters and the unserved majority. Whereas the first houses (tiers A and B) were connected quickly, adoption began to slow, as depicted in Fig. 2. By the end of our fieldwork, approximately one-fourth of the households were connected to the mini-grid.

We observed that there were conflicts in the village resulting from the divide between those who could and could not afford electricity. For example, cables between the mini-grid poles were cut, and there were fights at a local bar. These conflicts occurred because not all villagers were satisfied with the fact that wealthy households created a larger gap in the social system by using electricity as a status symbol. As indicated in an interview with an expert in sustainable bioenergy, electricity access has a profound impact on individual social status. Thus, it may be implied that villagers wish to improve their social status by bringing others' attention to the electrical devices. For example, the secretary always had his door 


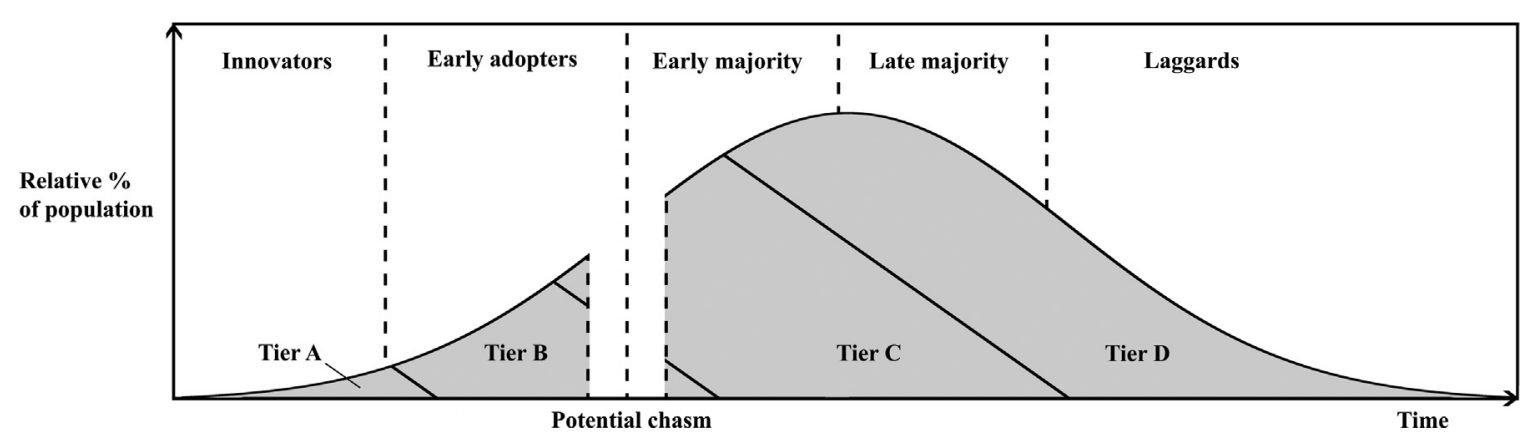

Fig. 2. Adoption curve and the chasm with four tiers of households.

Source: Adapted from Rogers [13] and Moore [30].

opened so that people could see his television. Moreover, he also had an unnecessary grid pole installed on his property to increase visibility. These actions relate to the above-mentioned issue that the secretary appeared to be not entirely accepted by all parts of the social system. The fact that he made use of such status symbols was not helpful in this context, and it did not reflect well on Pamoja, which collaborated with him closely and might subsequently have been suspected of prioritising him over others in the community.

\subsection{Dimensions of diffusion}

Without exception, all interviewees without an electrical connection noted that income was the only reason for not adopting electricity. In contrast, the adopters cited a number of other reasons, such as lack of awareness of the new technology and lack of knowledge about electricity and its benefits. As the focused interviews and observation suggest, heterophilous characteristics such as religion or household size did not affect the adoption decisions. As in previous literature, adopters' perceptions significantly impacted their decisions. Thus, to understand the perceptions within the social system of Tiribogo, we identify three dimensions of the diffusion process: technological, economic, and social. Within these dimensions, we identify various factors that influence diffusion. Because diffusion is a complex process [13], the dimensions and their factors are interrelated. The categorisation of our dimensions was inspired by diffusion theory [13], socio-technical perspectives [32,35-37,40], and other previous research conducted in Uganda $[15,16]$. Based on our empirical findings, we extend and categorise the results into these three dimensions.

\subsubsection{Technological dimension: emphasising relative advantage}

The focused interviews suggest that there is high awareness of the technology's relative advantages compared with conventional energy sources. In fact, electricity access has numerous benefits. The relative advantages of rural electrification are beyond what can be measured in economic terms [53]. As seen in the study by Mallett [39], one concern is that some low-income residents of rural areas exemplify day-to-day culture and do not have much interest in new technology, which could possibly slow adoption. To address this issue, information on relative advantages must be promoted so as to increase adoption. Therefore, it was advantageous that the potential users were already familiar with electricity, i.e., they had seen it in the large nearby cities, and some wealthier villagers in the community already used diesel engines. Our research outcome suggests that the villagers see a broad range of advantages in the new technology. These are primarily related to reliable services and a sustainable energy generation method, which must be carefully managed to become advantages. Then, it is the task of an energy service company to create technological awareness. Finally, advantages related to functionality must be promoted as benefits and in terms of productive usage.

First, the company must provide reliable services, especially when it is new to the social system. Pamoja promised to provide electricity service every day from $5 \mathrm{pm}$ until midnight. This was, however, often not fulfilled. Consequently, the villagers perceived Pamoja as unreliable, which created frustration and resistance from the early stage of diffusion. The power plant often began later or not at all because of mismanagement and technical problems, which could have been avoided with proper management. A Ugandan expert stressed that "fixed times must be communicated, and they [Pamoja] must make sure that electricity is really available then". In addition, the chairman expressed his concerns about acceptance if recurring errors such as power outages continued, particularly once the residents were required to pay for the services. Reliable electricity service plays a critical role when it is used for business purposes. Unreliable service reduces the relative advantages and could therefore slow adoption. The director of a large agricultural company stated in an expert interview that this could result in a situation in which wealthy villagers continue to use their diesel generators. This is a common practice among many Ugandan companies in agriculture because they do not trust the reliability of electricity provided by the national supplier and thus accept the higher costs of electricity generated by diesel engines. The issue of unreliable service was further highlighted during the interviews with villagers. Four respondents reported that electricity was not provided at the promised hours. Moreover, according to the survey, 22 of 24 villagers completely agreed that there must be no power outages, while the remaining two responded that they agreed.

The second advantage of the biomass-based system is that it is a sustainable energy generation method. Three villagers stated that they had a positive attitude towards Pamoja because their system generated electricity using local biomass residues. One young man stated that "it saves forests and it is better for the environment". During our fieldwork, the biomass was provided for free by supportive farmers. However, Pamoja had long-term business plans to purchase biomass from all farmers in the village. This plan may generate additional income for the villagers and, hence, support local development while ensuring a stable supply for the power plant. To generate the revenue to fund the biomass, Pamoja planned to sell the charcoal residue of the gasification process to briquette manufacturers. Alternatively, it could be used as fertiliser by local farmers. Nevertheless, Pamoja faced a challenge regarding waste management. The gasification process produces wastewater, which must be properly disposed of, or it can contaminate a well's groundwater.

Creating technological awareness plays a significant role in the adoption process. This requirement is aligned with the trialability attribute of innovations. According to Rogers [13], innovations 
that can be tried on a limited basis are more likely to be adopted. To establish collective confidence in a new innovation, the targeted community should be educated about electricity not only in terms of benefits but also regarding devices, their electricity consumption, and safety issues. As will be shown in the following paragraph, there was a lack of understanding about the electrical devices and their consumption. Regarding safety, multiple villagers raised questions during the interviews, e.g., whether it was dangerous to touch the cables or metre boxes and what to do if it rained because they had heard rumours that water was dangerous for electricity. In fact, the surveys showed that the villagers were interested in receiving more information about electricity: 21 of 23 completely agreed that they "would like to attend a workshop about electricity and how it works", while 2 responded that they agreed.

Moreover, the functionality of electricity provided by a biomassbased system was perceived as superior to other energy sources. According to Okello et al. [9], there are a number of advantages to using bioenergy technology, such as health benefits and energy security. Regarding the relative advantages of the innovation, the most frequent answer, stated by 13 interviewees, was that the provided electricity was perceived to give brighter light than kerosene lamps. One respondent reported an educational benefit as an outcome of electricity access because her children could read books at night. Eight villagers noted that they preferred to have electricity all night long to provide a security light outside the house. One man stated: "I would like to have it until 6 am for safety reasons. I want to be able to look for my animals if they make noises at night." An interviewee with a small solar system noted that "it [electricity from the mini-grid] is more powerful, and also provides electricity in the rainy season", which is also related to the reliable service advantage. In addition, eleven interviewees noted health benefits as a major advantage of electricity access compared with the existing energy sources such as firewood and kerosene lamps. The advantages of electricity access can, however, be misconceived. Some of the advantages of electricity as perceived by the villagers were in fact not technically appropriate, e.g., using scarce electricity for cooking, as indicated by one respondent who planned to purchase an electric stove to reduce cooking time. Owing to a lack of knowledge about electricity consumption and costs, one household had already purchased eight light bulbs, an iron, a television, and a sound system. In our opinion, communicating appropriate relative advantages deserves more attention. As recommended by the CREEC head of biomass energy, productive usage is a relative advantage related to functionality that should be promoted intensively to foster local development. In fact, 20 interviewees stated that they considered initiating businesses because of the new availability of electricity; nine of them already had concrete plans. Many respondents were revealed to want to open a bar with a refrigerator, lights, and a television. Only three respondents reported plans to use electricity to improve productivity in their existing (agricultural) businesses. In our opinion, the company should promote the use of electricity for agricultural activities, such as maize processing, welding, poultry food processing, and water pumps, to increase productivity and efficiency. During our fieldwork, electricity was used mainly for leisure purposes; we observed that a number of households bought televisions immediately after being connected to the mini-grid.

\subsubsection{Economic dimension: building a viable financial system}

In addition to relative advantages compared with existing solutions, another main criterion that affects adopters' decisions to adopt an innovation is price. Thus, to encourage electricity adoption, its use should be financially attractive, especially among low-income households. The adopters must be willing and able to pay for the services provided by energy companies. In this study, we identify four factors that affect the adoption in Tiribogo: affordability, payment system (i.e., how to pay), investment costs, and appropriate tariffs.

Affordability is crucial from the economic perspective of energy companies and, hence, an important factor for determining the site of an electrification project. Companies should aim to target communities that have sufficient income to afford the innovation [54]. The head of the biomass energy section of CREEC stated that they had developed a model to determine sites for electricity projects based on existing demand and incomes. The result reported by CREEC for the application of their model to Tiribogo suggested that the village was a potential site for Pamoja.

The payment system should be designed based on the adopters' existing payment methods to increase the compatibility. In Uganda, mobile payment is very popular. At the end of 2013, MTN-one of Uganda's major mobile network operators-had approximately 8.8 million subscribers. Among those, approximately 5.2 million, corresponding to more than $15 \%$ of the country's population, were registered for the company's mobile payment services [55]. In Tiribogo, every household owned at least one mobile phone: 28 out of 31 interviewees saw no obstacle in paying their bills with mobile money transaction, and 16 of those already used mobile payments to send money to family members or business partners; they were convinced that it would save time and be safer than cash. An expert in bioenergy who operated in sub-Saharan Africa confirmed that "it [mobile payment] is very transparent and there is almost no room for cheating". He further supported the suitability of mobile payment to pay for electricity services.

Investment cost can be a barrier to the diffusion of electricity. In particular, Okello et al. [9] highlight that high investment costs for users could hinder the introduction of bioenergy technology in Uganda. To connect households to the mini-grid, Pamoja charged an initial connection fee of 100,000 UGX. In addition, each household had to pay for the wiring inside the house, which costs between 100,000 and 200,000 UGX, depending on the individual agreement. This wiring was performed by an electrician from the neighbouring village, who exploited his monopoly position by overcharging Tiribogo villagers. This issue could have been avoided if the company had offered its own or at least an alternative solution. Thus, in total, households incurred an investment cost of at least 200,000 UGX, which is equal to several months of income for a tier D household. Hence, despite their willingness to pay, the majority of the Tiribogo villagers were unable to afford electricity immediately because of a lack of savings. Uganda is a country with very short cash flow cycles. According to an interview with the director of a large agricultural company, this applies not only to farmers but also to Ugandan companies, whose employees are paid on a daily basis. Accordingly, the respondents stated that they had to wait for later harvesting seasons. It should also be noted that households were connected to the grid not only because they could afford the investment costs but also because of social complications. For example, it was revealed that some villagers were connected to the grid earlier because of their personal relationship with the secretary. These complications emphasise the need for a company to maintain transparent financial arrangements.

Finally, finding appropriate tariffs that fit the adopters' budgets is an important criterion for the promotion of electricity adoption and regulation. It was indicated in an expert interview that rural Ugandans often believe that the products and services of companies from developed countries should be offered free of charge. This misconception emphasises the need to communicate regarding electricity tariffs early in the process. It was revealed in the survey that all respondents were willing and able to "pay a certain amount of money for electricity each month". Because of the short cash 
flow cycles in Uganda, the company could have offered a flexible payment system. When asked whether they would prefer a fixed price each month or a price based on usage, the interviewees were inconclusive. One woman noted that her monthly income varied significantly and, thus, that a usage-based tariff was preferable. An inclusive tariff system is crucial for the diffusion process because it can help to increase social acceptance and achieve critical mass. Regarding the use of electricity as a status symbol, as described in Section 5.1, exponentially increasing tariffs can offer a solution for the issue of excessive private usage. Moreover, tariffs should be designed to promote productive usage, as noted in Section 5.2.1. For example, the tariff can be lower during the daytime, when electricity is utilised more for work purposes, and higher rates can be charged in the evening, when it is instead used for leisure purposes.

\subsubsection{Social dimension: collaborating with local actors}

When entering a new social system with a disruptive innovation, it is important for foreign firms to collaborate with local actors. The firm needs to understand the local market, earn trust, create awareness, and provide insights about the innovation. Within this social dimension, we place a particular focus on the actors, as emphasised by Stern [35]. We identify the following factors: partnering with local experts, incorporating local inhabitants with special attention to opinion leaders, utilising appropriate communication channels, and managing users' expectations properly.

A foreign energy company that attempts to enter rural markets in a developing country should partner with local experts. As explained in Section 3, Pamoja initiated contact with two main local actors: CREEC and a Ugandan site manager. These contacts proved to be of immense importance in overcoming the difficulties of establishing the electrification project and for developing a wide network of valuable local contacts. Although collaboration with CREEC was ultimately valuable, working with the site manager was sometimes difficult with respect to communication and control. Another complication was that the site manager lacked sufficient technical expertise regarding electrification and, thus, depended on external support. Unlike the collaboration with CREEC, which was entirely based on expertise, the collaboration with the site manager was based on personal contacts. One lesson learned is that, when choosing local partners, in addition to expertise, foreign firms should also consider characteristics such as trustworthiness, reliability, and commitment.

Additionally, a company should incorporate local inhabitants in the process to gain trust. This is of particular importance for foreign firms. For Pamoja, the roles of two opinion leaders, the chairman and the secretary of the local committee, proved to be crucial. The chairman appeared to be positive about the electrification project but was not completely convinced by the project because of concerns about reliability, as elaborated in Section 5.2.1. Despite the more influential position of the chairman, Pamoja's site manager elected to collaborate closely with the secretary, who was very supportive and convinced about the electrification project. The secretary became the most important contact person for issues related to the project. He, however, had limited technical knowledge about electricity, which may have led to spreading of incorrect information. He was also the person who organised meetings concerning the project and was even assigned by the site manager to collect the connection fees, which, in our opinion, should have been the responsibility of the energy service company.

For effective planning of a diffusion process, proper utilisation of communication channels is of great importance [13]. Mass media such as newspapers, radio broadcasts, and television are common but costly channels for spreading information. Thus, Pamoja chose direct communication using interpersonal channels instead. This approach allowed them to explain the new technology, discuss potential advantages, create technical awareness, and explain money-related issues such as tariffs and connection fees. According to Okello et al. [9], lack of awareness is stressed as an obstacle for bioenergy technology and could, based on our findings, be properly managed through appropriate communication channels. An interview with the expert in the field of the environment and development confirmed the more effective use of this channel, especially for small companies operating in sub-Saharan Africa. This is aligned with diffusion theory, which states that distributing information through interpersonal communication is more likely to be effective in terms of achieving mutual understanding [13]. As explained earlier in Section 5.2.2, Pamoja used the secretary as a channel to reach the villagers. Working with an opinion leader helped, at least to some extent, to raise interest and trust and create awareness among individual households about the functionality of electricity. The challenge with this construct is that the information was communicated via multiple layers. Information from Pamoja's head office in Stockholm was spread to the site manager, to the secretary, and then to the villagers. This resulted in inconsistent, uncertain, and confusing information for the end users. In fact, 19 of 23 respondents responded "completely agree" to the survey question on whether the information provided by the company regarding electricity, prices and services was unclear.

The challenge in communicating information is managing users' expectations. Direct and clear communication, e.g., at meetings, at the local school, and via hand-outs or posters-as was done by CREEC for its projects-is important for avoiding vague promises and for reducing incorrect expectations and suspicions about supportive innovators and opinion leaders. For instance, the advisor of the local farmers association stated that some people accused him of being paid by Pamoja for helping the company. In addition, three interviewees believed that the secretary charged different connection fees and prioritised certain households depending on their personal relationships. During our fieldwork, electricity was offered in the village free of charge because the project was still in a trial period and had recurring errors. Unfortunately, this phase of trialability was not communicated to the villagers. In fact, it was an opportunity for both Pamoja and the users to test, give feedback and improve the system, which would have been beneficial for similar future electrification projects. Because of the multiple layers of communication, there was an insufficient feedback loop to the company's head office. It should also be noted that managing users' expectations is related to the fact that the company should provide reliable services, as discussed in Section 5.2.1.

\section{Conclusion and implications}

Our research objective was to analyse the factors that influenced the adoption of renewable electricity through a mini-grid, from the individual rural household perspective, in Uganda. Based on our empirical investigation, we identified three interrelated dimensions, each with a set of factors that affected the acceptance of the innovation and hence its diffusion. First, there is the technological dimension, particularly the emphasis on the relative advantages of the new technology. Second, in terms of the economic dimension, a viable financial system for adopters is necessary, particularly in such a low-income market. Third, we shed light on the social dimension, particularly the collaboration of foreign firms with local actors. If even one of these dimensions is not managed efficiently, diffusion can be hampered. We summarise the results as particular focus areas and management implications in Table 1.

Although our results are based on a single case study, the findings have general implications for foreign entities who attempt to enter a market in developing countries. Our findings are of 
Table 1

Research outcomes and their respective management implications structured into dimensions.

\begin{tabular}{|c|c|c|}
\hline Dimension & Particular focus & Management implications \\
\hline Technological & $\begin{array}{l}\text { Relative advantages of the } \\
\text { disruptive innovation }\end{array}$ & $\begin{array}{l}\text { - Provide reliable services } \\
\text { - Provide electricity from sustainable energy sources } \\
\text { - Create technological awareness among the potential adopters } \\
\text { - Promote functionality of electricity access, especially for productive usage }\end{array}$ \\
\hline Economic & Financial aspects for the adopters & $\begin{array}{l}\text { - Target communities that can afford the technology } \\
\text { - Provide a manageable payment system for the adopters } \\
\text { - Minimise investment costs to accelerate the diffusion process } \\
\text { - Set appropriate tariff plans, i.e., affordable, flexible, inclusive, and encouraging productive usage }\end{array}$ \\
\hline Social & Collaboration with local actors & $\begin{array}{l}\text { - Partner with local experts } \\
\text { - Incorporate local inhabitants } \\
\text { - Utilise proper communication channels } \\
\text { - Manage users' expectations properly }\end{array}$ \\
\hline
\end{tabular}

particular importance for foreign energy service companies who attempt to penetrate the rural energy sector in sub-Saharan Africa. We further suggest that a lack of understanding of the local communities can lead to the failure of diffusion attempts.

This study contributes to the existing literature on the diffusion of innovation in developing countries and offers empirical insights. It underpins the importance of opinion leaders but also reveals complications deriving from their influence. Moreover, particularly in the developing country context, where there are numerous areas of improvements and opportunities, it is likely that an innovation can be quickly adopted if the social system has long been seeking a similar solution. However, adoption must occur under the condition that the innovation is affordable and economically viable. In addition, our study sheds light on the technology transfer process from developed to developing countries. Specifically, we provide perspectives on a foreign energy service company that invested in a sub-Saharan country, which is still lacking in the existing body of literature.

Nevertheless, our study also has some limitations. Because of the time constraints on our fieldwork, the entire adoption curve could not be illustrated, and in addition, our interview and survey sample sizes were too small to yield generalisation. Extended observation time, a more quantitative approach, and the investigation of multiple electrification attempts at the various sites of the different energy service companies in sub-Saharan regions could help to enhance the understanding of diffusing disruptive innovations in developing countries, which could be an area of interest for future research.

\section{Acknowledgements}

We are grateful to the Swedish International Development Cooperation Agency (Sida), which provided funding for the fieldwork in Uganda. In addition, this study is partly funded by KTH Royal Institute of Technology and Royal Thai Government Scholarship. Lastly, we greatly appreciate the valuable and constructive comments from five anonymous reviewers of Energy Research $\mathcal{E}$ Social Science and the guest editor of this Special Issue.

\section{References}

[1] Bazilian M, Pielke Jr R. Making energy access meaningful. Issues Sci Technol 2013;29(4):74-8.

[2] Mukasa AD, Mutambatsere E, Arvanitis Y, Triki T. Wind Energy in Sub-Saharan Africa: financial and political causes for Africa's under-development of wind energy//Development of Wind Energy in Sub-Saharan Africa. Energy Res Soc Sci 2015:5:90-104.

[3] International Energy Agency. World energy outlook 2013; 2013.
[4] Hancock K. Renewable energy in Sub-Saharan Africa: contributions from the social sciences. Energy Res Soc Sci 2015;5:1-8.

[5] Fri RW, Savitz ML. Rethinking energy innovation and social science. Energy Res Soc Sci 2014;1:183-7.

[6] Bruntland G. Our common future: the world commission on environment and development; 1987.

[7] Musinguzi WB, Okure MA, Sebbit A, Løvås T. Small-scale CHP for rural electrification in Uganda - the state-of-the-art and prospective development. In: Second International Conference on Advances in Engineering and Technology, Working Paper. 2011.

[8] Ugandan Bureau of Statistics. Uganda national household survey 2009/2010; 2010

[9] Okello C, Pindozzi S, Faugno S, Boccia L. Appraising bioenergy alternatives in Uganda using strengths, weaknesses, opportunities and threats (SWOT) - analytical hierarchy process (AHP) and a desirability functions approach. Energies 2014;7(3):1171-92.

[10] Mahat I. Implementation of alternative energy technologies in Nepal: towards the achievement of sustainable livelihoods. Energy Sustain Dev 2004;8(2):9-16.

[11] Kanagawa M, Nakata T. Assessment of access to electricity and the socioeconomic impacts in rural areas of developing countries. Energy Policy 2008;36(6):2016-29

[12] World Bank. The welfare impact of rural electrification: a reassessment of the costs and benefits. World Bank; 2008.

[13] Rogers EM. Diffusion of innovations. 5th ed. New York: Free Press; 2003

[14] Okello C, Pindozzi S, Faugno S, Boccia L. Development of bioenergy technologies in Uganda: a review of progress. Renew Sustain Energy Rev 2013;18:55-63.

[15] Buchholz T, Rametsteiner E, Volk TA, Luzadis VA. Multi criteria analysis for bioenergy systems assessments. Energy Policy 2009;37(2):484-95.

[16] Okello C, Pindozzi S, Faugno S, Boccia L. Bioenergy potential of agricultural and forest residues in Uganda. Biomass Bioenergy 2013;56:515-25.

[17] Hobday M, Boddington A, Grantham A. An innovation perspective on design: Part 1. Des Issues 2011:27(4):5-15.

[18] Schumpeter JA. The analysis of economic change. Rev Econ Stat $1935 ; 17(4): 2-10$

[19] Christensen C. The innovator's dilemma: when new technologies cause great firms to fail. Harvard Business Review Press; 2013.

[20] Bower JL, Christensen CM. Disruptive technologies: catching the wave. Harv Bus Rev 1995;73(1):43-53.

[21] Rogers EM. Diffusion of preventive innovations. Addict Behav 2002;27(6):989-93.

[22] Prahalad CK. The fortune at the bottom of the pyramid, revised and updated 5th anniversary edition: eradicating poverty through profits. FT Press; 2009.

[23] Prahalad CK, Hammond A. Serving the world's poor, profitably. Harv Bus Rev 2002;80(9):48-59.

[24] Karnani A. The mirage of marketing to the bottom of the pyramid. Calif Manage Rev 2007:49(4):90-111.

[25] Reddy AK. Barriers to improvements in energy efficiency. Energy Policy $1991 ; 19(10): 953-61$

[26] Kshetri N. Barriers to e-commerce and competitive business models in developing countries: a case study. Electron Commerce Res Appl 2008;6(4):44352.

[27] Aubert JE. Promoting innovation in developing countries: a conceptual framework, vol. 3554. World Bank Publications; 2005

[28] Wüstenhagen R, Wolsink M, Bürer MJ. Social acceptance of renewable energy innovation: an introduction to the concept. Energy Policy 2007;35(5):2683-91.

[29] Troncoso K, Castillo A, Masera O, Merino L. Social perceptions about a technological innovation for fuelwood cooking: case study in rural Mexico. Energy Policy 2007;35(5):2799-810.

[30] Moore GA. Crossing the chasm: marketing and selling high-tech products to mainstream customers. New York: Harper Business Essentials; 2002.

[31] Greenhalgh T, Robert G, Macfarlane F, Bate P, Kyriakidou O. Diffusion of innovations in service organizations: systematic review and recommendations. Milbank Q 2004;82(4):581-629. 
[32] Geels FW, Schot J. Typology of sociotechnical transition pathways. Res Policy 2007;36(3):399-417.

[33] Rip A, Kemp R. Technological change. Battelle Press; 1998. p. 327-99 [chapter 6].

[34] Geels FW. Technological transitions as evolutionary reconfiguration processes: a multi-level perspective and a case-study. Res Policy 2002;31(8):125774.

[35] Stern PC. Individual and household interactions with energy systems: toward integrated understanding. Energy Res Soc Sci 2014;1:41-8.

[36] Geels FW, Smit WA. Failed technology futures: pitfalls and lessons from a historical survey. Futures 2000;32(9):867-85.

[37] Lente HV [Doctoral dissertation] Promising technology: the dynamics of expectations in technological developments. Universiteit Twente; 1993.

[38] Shyu CW. End-users' experiences with electricity supply from stand-alone mini-grid solar PV power stations in rural areas of western China. Energy Sustain Dev 2013;17(4):391-400.

[39] Mallett A. Social acceptance of renewable energy innovations: the role of technology cooperation in urban Mexico. Energy Policy 2007;35(5):2790-8.

[40] Müggenburg H, Tillmans A, Schweizer-Ries P, Raabe T, Adelmann P. Social acceptance of PicoPV systems as a means of rural electrification - a sociotechnical case study in Ethiopia. Energy Sustain Dev 2012;16(1):90-7.

[41] Ahlborg H, Sjöstedt M. Small-Scale Hydropower in Africa: socio-technical designs for renewable energy in a Tanzanian villages. Energy Res Soc Sci 2015;5:20-33.

[42] Ulsrud K, Winther T, Palit D, Rohracher H. Village-level Solar Energy in Africa: accelerating solar power through a socio-technical design in Kenya. Energy Res Soc Sci 2015;5:34-44.
[43] Buchholz T, Da Silva I. Potential of distributed wood-based biopower systems serving basic electricity needs in rural Uganda. Energy Sustain Dev 2010;14(1):56-61.

[44] Kirkels AF, Verbong GP. Biomass gasification: still promising? A 30-year global overview. Renew Sustain Energy Rev 2011;15(1):471-81.

[45] World Bank. Uganda overview; 2014. Retrieved from http://www.worldbank. org/en/country/uganda/overview

[46] Gillham B. Case study research methods. Continuum 2000.

[47] Flick U. An introduction to qualitative research. Sage; 2014.

[48] McDermott R, O’Dell C. Overcoming cultural barriers to sharing knowledge. Knowl Manage 2001;5(1):76-85.

[49] Bickman L, Rog DJ, editors. The Sage handbook of applied social research methods. Sage; 2009.

[50] Spradley JP. Participant observation. Holt, Rinehart and Winston New; 1980.

[51] Sriwannawit P, Laestadius S. Diffusion of photovoltaic systems for rural electrification in Thailand. Int J Energy Environ 2013;4(1):49-58.

[52] Turnheim B, Geels FW. Regime destabilisation as the flipside of energy transitions: lessons from the history of the British coal industry (1913-1997). Energy Policy 2012;50:35-49.

[53] Sriwannawit P. Transition towards off-grid photovoltaic systems: is price the final answer? Energy Procedia 2014;57:1546-54 [Special Issue from ISES Solar World Congress].

[54] Griliches Z. Hybrid corn and the economics of innovation. Science 1960;132(3422):275-80

[55] Press Box. MTN Uganda hits 8.8 million subscriber base; 2014. Retrieved from http://www.mtn.co.ug/About-MTN/News-Room/2014/March/March-2014MTN-Uganda-hits-8.aspx 